\title{
BODAS DE OURO DE UM PROGRAMA PRECURSOR E EXITOSO
}

\author{
Floriano de Azevedo Marques Neto ${ }^{1}$
}

No Brasil, um programa de pós-graduação em Direito completar 50 anos não é pouca coisa. Um programa das dimensões e com as multiplicidades do da Faculdade de Direito da USP manter-se forte e ativo por esse tempo todo é, então, um verdadeiro marco. O presente texto procurará expor os méritos e os desafios do programa de pósgraduação do Largo São Francisco, ao mesmo tempo em que procurarei refletir um pouco sobre a função de uma pós-graduação stricto sensu estrito senso na área jurídica.

O surgimento do programa, no alvorecer dos anos 1970, inseriu-se numa inflexão importante do ensino jurídico no Brasil. Aliado às mudanças que se desenhavam para o ensino superior, o programa procurava introduzir uma sistemática de formação de quadros de pesquisadores e de futuros docentes. Embora se possa tecer as mais diversas críticas à reforma universitária de 1968, o fim das cátedras criou a necessidade e a oportunidade para a formação de quadros acadêmicos fora do processo de abdução e servilidade que marcava a relação entre assistentes e catedráticos. Contudo, a força da tradição ainda ditava a regra. Seria um dos maiores desafios evitar que se transpusesse para o programa de pós-graduação que se iniciava simplesmente a sistemática de áreas controladas pelos docentes convertidos em titulares de departamentos.

$\mathrm{O}$ fato é que o programa se iniciou muito mais organizado em torno das áreas dos departamentos consolidados ou de concentração dos docentes mais destacados, que passavam a assumir na pós-graduação disciplinas de sua familiaridade ou pesquisa.

É natural, então, que o programa não tenha assumido desde o início uma configuração como a que viria a ser posteriormente exigida. Linhas de pesquisa, projetos acadêmicos, orientações e pesquisas centradas em núcleos temáticos coerentes e delimitados no tempo não foram, nas primeiras décadas, o eixo estruturante dos programas. Mais importante eram os temas e as pesquisas ao alvedrio dos professores mais graduados vinculados ao programa.

Isso fez com que a estruturação original, fundante, do programa permitisse que ele se construísse como um programa amplo, grandioso e um tanto fragmentado, com ilhas constituídas originalmente por líderes (sucessores dos donos das cátedras à época recém-extintas enquanto tal).

Outro tema que marcou de forma desafiadora o programa logo nos seus primeiros anos foi a oposição entre um programa acadêmico, voltado a reflexões e

\footnotetext{
Professor Titular da Faculdade de Direito da USP. Diretor da FDUSP.
} 
pesquisas mais avançadas e direcionado à formação de quadros docentes, versus um programa com uma visão mais profissionalizante, de atualização profissional, mais na linha do que hoje se denomina programas de educação continuada.

A esses desafios de formulação original, foi incorporando-se com o tempo um terceiro problema, literalmente crescente. O programa foi aumentando e se tornando duplamente grande: de um lado, com uma multiplicidade de áreas e linhas de pesquisa; de outro, com um número exponencial de docentes e de discentes.

Apesar de tudo isso, estou certo e seguro de que o programa de pósgraduação da Faculdade de Direito da USP é a um só tempo atípico e largamente bem-sucedido. Muitas das teses defendidas em seu âmbito ao longo dessas décadas se tornaram marcos da inovação e do pensamento jurídico. Algumas das posições estudadas e defendidas tornaram-se textos de lei ou orientações predominantes na jurisprudência. Inúmeras se transformaram na base de livros que marcam os diferentes ramos do Direito.

$\mathrm{Na}$ formação de docentes e pesquisadores, pode-se dizer sem chance de errar que o programa de pós-graduação da Faculdade de Direito da USP formou uma parcela relevante daqueles que hoje ocupam uma posição de liderança e coordenação em outros programas de pós-graduação jurídicos pelo Brasil afora. A tal ponto que chegamos à situação contraditória na qual muitos de nossos desafetos, que ora e vez se mobilizam para subavaliar nosso programa no âmbito da Capes, doutoraram-se na nossa Faculdade de Direito. Esse é um sinal de que o programa é tão amplo e bem-sucedido que produz tanto profissionais de ponta, pesquisadores e docentes que fazem a diferença, quanto aqueles que, incapazes de pontificar, dedicam-se a detratar.

Esse sucesso pode se medir tanto quantitativa como qualitativamente. Não se tem notícia de um programa, mesmo fora do país, que resulte em tantas dissertações e doutoramentos bem-sucedidos. O percentual de conclusão é bastante alto, e essa quantidade não é feita à base do aviltamento de exigências ou de facilitações e compadrio. Tanto que, qualitativamente, são frequentes os prêmios de mestres e doutores formados na FDUSP pelos trabalhos que produziram nos mais diferentes âmbitos. Apesar de, vez ou outra, um trabalho escapar ao nível geral de excelência, a avassaladora maioria ao longo desses anos revelou pesquisa séria, inovação e produção útil ao saber jurídico.

Esse sucesso se deve a alguns fatores. O programa foi dirigido ao longo destas cinco décadas por professores que, além da dedicação ímpar, reuniam a mais alta capacidade acadêmica. São muitos nomes, mas dos que me recordo é necessário lembrar de José Eduardo Faria, Ada Pellegrini Grinover, Otávio Bueno Magano, Eros Grau, Ignácio Poveda Velasco, Fernando Dias Menezes de Almeida e nosso atual líder Fernando Facury Scaff. Mais do que isso, nosso programa já ofereceu um número relevante de coordenadores de área da Capes. 
Essa constatação, porém, não pode esconder aquilo que ainda precisa ser feito, e é muito. Antes de olhar para o futuro do programa, gostaria de dar minha visão de um programa de pós-graduação em Direito.

Tenho comigo que, diferentemente da graduação - que deve buscar transmitir conhecimentos consolidados, ainda que de forma crítica, e capacitar os graduandos para sua atuação futura como profissionais ou pensadores do Direito -, um programa de pós deve estar dirigido a desconstruir o saber jurídico consolidado. Isso não significa que um bom programa deve ser necessária e exclusivamente niilista, porém uma pós deve ser o ambiente propício para se questionar, desafiar e divergir do paradigma vigente. Isso, a meu ver, obriga não só que os docentes incentivem a reflexão crítica sobre o saber posto. Demanda também que os projetos aceitos para orientação e mesmo as disciplinas ofertadas propiciem essa visão. Pós-graduação em sentido estrito não é lugar de educação continuada.

$\mathrm{Na}$ área do Direito, é na pós-graduação que preferentemente se realizam as pesquisas jurídicas. Há atividade de pesquisa na graduação (na verdade, a iniciação científica), nos programas de pós-doc e na atividade regular de produção dos docentes, mas o ambiente ideal para a pesquisa acadêmica em Direito se desenvolver é mesmo a pós, seja com a instigação de reflexões e produção nas disciplinas, seja com a própria investigação necessária à elaboração de dissertações e teses. Nisso têm um papel fundamental as linhas de pesquisa e os projetos acadêmicos. É dever de qualquer programa os manter sempre atualizados, evitando que envelheçam pela inércia. É importante que eles apontem para novas fronteiras temáticas e de abordagem. Sem isso, a produção de pesquisa na pós-graduação ficará retrospectiva e repetitiva.

Além disso, a pós não pode se estruturar em áreas estanques. O Direito, já pude afirmar em mais de uma oportunidade, não é um jardim botânico construído com canteiros bem delimitados, cada qual com sua espécie. É uma grande floresta tropical, com as espécies misturadas e compondo um todo único a ser explorado, onde uma área interfere e depende da outra. Daí a relevância de pesquisas multiáreas, áreas de pesquisa comuns a mais de um departamento e disciplinas com vários docentes enredados em abordagens diversas de um mesmo tema. Ou seja, um programa de pós-graduação não pode padecer de eugenia temática; ele deve primar pela troca e pelo intercâmbio entre as áreas. É uma externalidade positiva termos um programa gigante e não sermos uma constelação de programas autônomos e com um único foco. Cumpre aos programas se intercambiarem e aos docentes assumirem o compromisso de cooperar entre si, sempre.

Tenho certa aversão a disciplinas de pós excessivamente expositivas, não dialógicas. Embora isso seja hoje objeto de crítica, admito que, na graduação, possa fazer sentido aulas expositivas no antigo modelo do dictamen docente. Mas, na pós, não. Igualmente também me apoquenta as disciplinas em que professores e alunos se 
sentem à vontade para tecer considerações aleatórias e sem metodologia alguma, como se estivessem numa roda de conversa. No meu entender, uma pós deve primar por aulas dialógicas, previamente preparadas pelo docente, com bibliografia de referência e alguma amarração. Esse é o modelo adotado em todos os centros de excelência e creio dever ser um modelo perseguido.

Por fim, um bom programa de pós-graduação deve externar sua produção. De preferência, produzir artigos fruto da cooperação docente e discente, seja pela pesquisa conjugada entre orientador e orientado, seja pela aproximação dos discentes de professores que trabalhem temas ou disciplinas associados a suas áreas de pesquisa. Isso por duas razões. Em primeiro lugar, porque é dever da pós, como alavancadora de pesquisas, propiciar que a produção decorrente desse esforço seja compartilhada com a comunidade acadêmica e científica. Ainda padecemos bastante na área do Direito por não termos a tradição de diversas publicações renomadas que se valem do sistema de seleção de trabalhos por revisão pelos pares. Mas temos avançado nisso. Em segundo lugar, as publicações em coautoria de docentes e discentes são relevantes para permitir o compartilhamento do saber construído na pós com toda a sociedade, mesmo e principalmente no caso de trabalhos que contestem posições consolidadas ou apontem para linhas inovadoras. Isso enseja que tais reflexões multipliquem-se e se retroalimentem, fazendo avançar trilhas de pesquisa que, encapsuladas num programa, poderiam não avançar.

Essa é a visão pessoal que tenho da utilidade e dos objetivos de um programa de pós-graduação. Não me arrisco a dizer que, no seu cinquentenário, o programa de pós da Faculdade de Direito da USP esteja totalmente dentro do que considero ideal. Embora esteja muito bem nesses itens, ainda há bastante por fazer, e devo reconhecer que o enorme esforço que a atual direção do programa FDUSP - liderado pelos professores Fernando Facury Scaff e Ana Elisa Bechara, dois titãs da boa causa - está empreendendo faz o programa avançar muito nesse sentido.

Por ser um programa gigantesco, a primeira meta a ser perseguida é tornálo menos assimétrico (sem anular diferenças) e mais funcional. A mudança nos critérios de credenciamento e recredenciamento e os programas de apoio a publicações e de capacitação para manejar os sistemas de relatórios e avaliação têm produzido frutos. $\mathrm{O}$ incentivo a produções não individuais também tem ajudado muito nesse sentido. Produzse muito no programa. Há que se desconcentrar essa produção.

Outro vetor relevantíssimo é o que eu chamaria de "desensimesmamento" do programa, com incentivo às atividades multiáreas, interdepartamentais e mesmo com unidades de fora do programa. Essa troca tem evoluído muito nos últimos anos, com disciplinas integradas por diversos professores e outras com participação de professores convidados de outros programas. 
Um desafio ainda maior é o da internacionalização. Aqui não se trata de uma dificuldade cultural propriamente, mas de uma dificuldade operacional e logística. Internacionalizar o programa não é apenas publicar artigos fora do país ou receber professores estrangeiros. Isso o programa já faz e está ampliando. O desafio maior é intercambiar docentes e discentes. Aqui há a barreira, menor, do financiamento de bolsas, e, também, a grande barreira da língua. Mesmo os nossos vizinhos latino-americanos padecem de grandes dificuldades com o português. O fato é que exportamos mais discentes do programa do que importamos. Isso deve ser objeto de esforço especial. Inclusive aumentando-se a oferta de disciplinas em inglês e espanhol.

Desafio não menor é o da inclusão. Apostar em um programa mais plural e diverso é de suma importância. Porém, no programa de pós, o desafio é ainda maior do que aquele que estamos vencendo na graduação. Há, de um lado, a impreterível característica de liberdade e autonomia dos docentes para selecionar seus orientandos. Isso não deve ser alterado, pois impor orientandos a um docente é premissa para processos tortuosos e malsucedidos de orientação. De outro lado, um programa que prima pela excelência deve combinar essa excelência com a diversidade e a inclusão. Por exemplo, o domínio de uma língua estrangeira, essencial para atingir o vetor da universalização, pode ser diferido, mas não dá pra simplesmente suprimi-lo. O apoio à formação dos discentes, especialmente em línguas, é vital. Nesse sentido, o recém-lançado programa, concebido pela coordenação do programa, com oferta de vagas adicionais para inclusão é um ótimo início.

Outro vetor, já referido, é a revisão, sistematização e atualização permanentes das linhas de pesquisa. Respeitada a autonomia dos docentes, devese incentivar que essas linhas sejam consentâneas com as premissas que já divisei anteriormente. Essa talvez seja a mais difícil missão para um programa consolidado, porém vivo.

Concluo saudando o programa, já quase tão vetusto como eu. Que ele continue sempre vigoroso, bem-sucedido e referenciado por todos. Essa, sim, é sua missão. 